\title{
Effect of Implementing Evidence Based Nursing Guideline on Nurses' Performance Related to Care Providing for Children at Pediatric Intensive Care Unit
}

\author{
Mabrouka Atia Nada \\ Pediatric Nursing, Menofia University
}

\begin{abstract}
Evidence-based nursing guideline increases the quality of patient care and closes the gap between research outcomes and practice, Evidence Based Practice (EBP) is the use of current research evidence combined with clinical expertise as well as patient values to formulate sound interventions that ultimately improve the quality of patient care .Aim of the study: was to determine the effect of implementing evidence based nursing Guideline on nurses' performance related to care providing for children at Pediatric Intensive Care Unit. A quasi-experimental research design was used. Subjects and Method: A conveniences sampling of 40 nurses. Two tools were used to collect the data: Sociodemographic characteristic, nurses' knowledge of Evidence Based Nursing guideline and nurses' practice of Evidence Based nursing by using observational check list. The results revealed that significant improvement in nursing knowledge and practice after the implementation of Evidence Based nursing guideline. Conclusion most of the nurses have poor knowledge and practice score pre implementation and significant increase post implementation. Recommendation: Nurses should provide knowledge and practice in accessing and appraising research that is relevant to their practice guideline. Besides, it is also crucial that the organizations should provide the facilities and support in implementing evidence-based performance guidelines to optimize child nursing care.
\end{abstract}

Keywords: Evidence Based Nursing Guideline, performance, Pediatric intensive care unit. 


\section{Introduction}

Evidence-based practice is important to provide safe, quality care and improved patient outcomes ${ }^{(1)}$. Evidence based practice is considered to be an important aspect of quality care and therefore' an essential requirement for Magnet designation $^{(2)}$.

The evidence based process is to identify a problem in current practice which would represent a trigger for change in practice. The first step is followed by the second step which entails a review and critique of relevant literature. The third step is to identify research evidence that supports the change in clinical practice. The final step is to implement the change in practice and monitor the outcomes ${ }^{(3)}$.

Evidence based practice and nursing can be embraced and linkage practised without losing the art and the caring side of nursing while providing care that is still individualized and patient centered. Evidence-based practice is regard as foundational to quality care and has been shown to low costs and variability in care (4). Healthcare leaders recognize EBP as an complementarity part of achieving quality outcomes and attaining a high reliability.

Evidence-based practice is much broader. It sets out to answer a clinical question by exploring all available research evidences, and then merged the clinician's expertise with the patients' preferences and values before recommending a practice change ${ }^{(4)}$. Process of evidence based practice similar the components of the nursing process which include: Identifying the clinical practice question or problem; Assessing the clinical appraisal components; Planning the implementation; Implementing the practice change; and evaluating the practice change ${ }^{(5)}$. Evidence-based practice enables nurses to provide a high-quality patient care based on research and knowledge rather than because "this is the way we have always done it" or based on traditions, myths, hunches, advice of colleagues, or outdated textbooks. For example, when clinical questions arise, should one look to a nursing textbook for the answers ${ }^{(4)}$. To improve EBP application, factors such as ability to review EBP literature, nurse education (qualification) and nurses' attitudes to EBP application should be given substantial attention in order to complete quality patient care ${ }^{(6,7)}$..Implementation must not only consider what knowledge to be implemented, but how knowledge is also facilitated in the context where it will be used ${ }^{(8)}$.Successful implementation is the function of knowledge, context and 
facilitation according to the frame work "Promoting action on Research Implementation in Health Care ${ }^{(9)}$.

\section{Significant of the problem}

Nursing is the backbone of most health care systems and core and specialist nursing practice needs to be evidencebased to ensure delivery of quality patient care. There is a significant gap between research and practice most of the nursing practices are based on ward routine and hospital guidelines rather than on the latest evidence. The Institute of Medicine ${ }^{(10)}$ has established a goal that $90 \%$ of healthcare decisions will be evidenced based by the year $2020^{(10,11)}$. Despite the confirmation on EBP, there is often a delay between research and implementation at the bedside. Barriers to research utilization and EBP adoption have been identified over the years. Assessing organizational culture has been identified as a necessary first step in to overcoming common barriers ${ }^{(12)}$.

\section{Aim of the study was to:}

Determine the effect of implementing evidence based nursing guideline on nurses' performance related to care providing for children at Pediatric Intensive Care Unit.

\section{Research hypothesis:}

Implementation of Evidence Based Nursing guideline expected to be improved nurses 'knowledge and practice related to care providing for children at Pediatric Intensive Care Unit

\section{Subjects and Method}

\section{Research design:}

A quasi-experimental research design was used

\section{Setting:}

This study was carried out at Pediatric Intensive Care Units of Menoufia University Hospital.

Subject:Conveniences sampling composed of 40 nurses were included in the present study.

- Age from 1 to 18 years

- Sepsis.

- Traumatic Injury.

- Shock.

- Stroke.

- Ruptured Brain Aneurysm.

\section{Tools of Data Collection}

Two tools were used in the present study:

Tool I: Part (I) Nurses' Socio Demographic Assessment Tool ; which included; nurses' years of experience at pediatric intensive care unit, age in years, educational degree, current position, sex and attendance of previous training courses related to evidence based performance.

Part II: Nurses' Knowledge of Evidence Based Nursing Guideline assessment Tool: prepared by researcher after review of 
recent and relevant research ${ }^{(13,14)}$.to assess nurses' knowledge related to evidence based nursing related to caring of children. It comprises 10 questions in a form of multiple choice questions such as; evidence-based practice in nursing is considered as a guide to successful implementation, definition evidence based performance understanding ,evidence based practice information, process of EBP implementation steps ,the patient ,intervention, compare, outcome and time PICOT framework guides, lower body temperature, endotracheal intubation route, ventilator humidifier change ,blood sample pain control and Kinetic versus standard beds

Nurses knowledge was be scored as following:

- Correct and complete answer was $\operatorname{scored}(2)$

- Correct and incomplete answer was scored (1)

- Wrong answer or don't know was $\operatorname{scored}(0)$

The total score of nurses' knowledge was calculated and classified into three levels as follows:

Less than $60 \%$ was considered as poor knowledge.

60- $74 \%$ was considered as fair knowledge.
75-100 \% was considered as good knowledge.

Tool II: Nurses performance of Evidence Based nursing guidelines by using observational check list. This tool was used to assess nurses' performance related to pediatric intensive care children care as follows: hand washing, use of a protective, use of open circuit aspiration system, use of closed circuit aspiration system ,use of oral route for endotracheal intubation, use of nasal route for endotracheal intubation, exercise frequency, breathing exercise, use of spirometer therapy, , frequency of ventilator circuit changes time, blood and fluid warmer machine or traditional warmer methods, frequency of bacterial filter changes, open versus closed suction systems with sterile water or saline, cold compressor sites or warm compressor , bladder training vacation with urinary catheter or not, Kinetic vs. standard beds ,replacement of humidifiers, axillary temperature measurements and venipuncture or drawing all blood sampling from central line.Some procedures was recommended and others was not be recommended.

The total score of nurses' performance was calculated and classified into three levels as follows: 
Complete and correct done was given score (1)

Incorrect or not done was given score (0)

The total score of nurses' performance was calculated and classified as follow:

Less than $75 \%$ was considered unsatisfactory practice.

From75to 100 was considered satisfactory

\section{Method}

1. An official Permission was carried out the study from the responsible authorities

2. Ethical and legal consideration :

a-Ethical committee approval was obtained

b-Natural of the study was not cause harm or pain for the entries sample .

c-Privacy and confidentiality was put into consideration regarding data collection

3. Study tools were developed by researcher based on review of related literature to assess nurses 'performance of evidence based nursing.

4. Tools Validity: Tools of data collection were translated into Arabic and investigated for content validity by three juries (two in Pediatric nursing from the Faculty of Nursing, Tanta University, and one of Medicine, Menoufia University who are experts' in such related field and selected to test the content validity of the instruments and to judge its clarity, comprehensiveness, relevance, simplicity, and accuracy. All of the remarks were taken into consideration; some items were re-phrased to reach the final version of the tools. The tools were regarded as valid from the experts' point of view.

5. . A pilot study was carried out on (4) $(10 \%)$ of nurses to test the tool for its clarity, applicability, feasibility and theses nurses will be excluded from the study and the necessary modification was done A Pilot study.

6. The suitable statistical test was used for testing questionnaire reliability.

7. Nurses' knowledge assessment tool was filled in the clinical area by the studied nurses in presence of the researcher (Tool I part II).

8. Nurses' performance Observation checklist was filled out by the researcher who will be available 2 days per week alternatively in different study settings to assess the actual nurses' performance before, immediately from application of intervention (Tool II).

9. Study phases: the present study was conducted within four phases: 
1-Assessment phase: It included assessment of nurses' knowledge and performance of evidence based nursing related to high risk children care using Tools I( part II) and II

2-Preparatory phase: It involves reviewing the national and international related literature concerning the studied topic and gathering the tools of the study.

\section{3-Implementation phase: The} intervention guidelines implementation included the following steps:

a. Setting objectives of the intervention guidelines.

b. Preparation of the content which covered the reasons behind the application of the session.

c. The evidence based guideline was conducted in the 4th sessions; two sessions per week. The time of each session was about 45-60 minutes.

d. Different methods and media of teaching was used including lectures, group discussion, demonstrations and hand outs .

e. The nurses were divided into four subgroups and every group consist of 10 nurses.
Evidence Based Nursing Guideline recommended practice at pediatric intensive care unit.

To identify relevant evidence, databases were searched (MEDLINE, EMBASE, PubMed, text book, CINAHL, Cochrane collaboration, a Database of Systematic Reviews and Register for Controlled Trials) .There are 15 strategies on the guidelines:

1: Hand washing and use of a protective gloves every approach child found a direct relationship between hand washing and protective gloves responses and participation in infection control projects. Increased hand washing and use of protective gloves frequency was found amongst those participating in such projects which may stem from heightened awareness about infection control measures ${ }^{(15)}$.

2: Use of closed circuit aspiration system, Preventing the healthcare worker from being exposed to aerosolized secretions, nurses answered that closed suction as the recommended suction system in prevention of spread of infection ${ }^{(16)}$.

3: Oral route for endotracheal intubation effect for drainage of subglottic secretions are specialized 
tubes with a separate dorsal lumen which suctioning through the lumen remove oral and gastric secretions from the subglottic space, preventing micro aspiration that could lead to a decrease in chest infection. Subglottic secretion drainage is associated with a decrease in infection incidence and the incremental cost of these tubes is considered to be reasonable given the burden of illness associated ${ }^{(16)}$.

4:Incentive Spirometry is a good idea to practise deep breathing and coughing, less pain, discomfort from wound following operation, reduce chances of chest infection, give patients a chance to involve in care and save staff time and costs ${ }^{(17)}$.

5:The available evidence suggests no patient harm and considerable cost savings associated with extended ventilator circuit change intervals. The maximum duration of time that circuits can be used safely is changes every week, which is the commonly practised; and change for every new patient as the same circuit should not be used on two different patients. The other participants mentioned that current guidelines suggest changes only for new patients or when circuits are soiled ${ }^{(18)}$.
6: Intravenous fluid or blood warmer machine used for emergency situations and even potential dangers. Using warm water to heat fluid bags may take more time to reach the required temperature and carries a risk of bacterial contamination. Electric warmers often need external batteries that take vital time to assemble and need to be kept. Some chemical reactions can heat fluid above normal body temperature, potentially damaging the blood product ${ }^{(19)}$.

7: Using of a breathing system filter, placed between the patient and the Ypiece of the breathing system, as the sole means of humidification in patients receiving mechanical ventilation in the ICU is based on a reduction in infection and colonization of patients with Pseudomonas $\operatorname{aeruginos}^{(20)}$.

8: Sterile water is more safe in maintaining patient electrolyte, especially on the first days of operation, nurses agree because sterile water more saves for electrolyte balance, save stock of fluid and money for patient ${ }^{(21)}$.

9: Warm water is widely used by the public to lower body temperature of children who have fever and could 
prohibit febrile seizures, warm stimulus on the surface of the skin is able to change the set-point in the hypothalamus; especially, the anterior causing vasodilation, also the warm compress can increase evaporation, conduction and even radiation. Compresses with warm water using a temperature of $\left(34-37^{\circ}\right)$ or lukewarm can make the outside temperature be felt warm and the body will interpret that the outside temperature is hot enough .Thus, the body will lower the thermostat controls in the brain so as not to increase the body temperature again which is also called the heat transfer by conduction system ${ }^{(22-23)}$.

10: Bladder and catheter patency solutions are used to protect the patency of bladder and catheter lumen that can become blocked by debris or encrustation. It is instilled into the bladder to dissolve alkaline crystals or remove debris from bladder and catheter lumen to remain patent and draining ${ }^{(24)}$.

11:Kinetic bed therapy decreases the incidence of nosocomial pneumonia and improves outcomes in critically ill mechanically ventilated child, decreases duration of mechanical ventilation and ICU length of stay as well as hospital length of stay complications $^{(26)}$.

12: Replacement of humidifiers is safely for at least 48 hours and may be able to be used for one week .These humidifiers provide active humidification of air in which the inspired gases pass across or over a heated water bath. Heated humidifiers may also contain heated wired circuit to avoid formation of ventilator tubing condensate. These humidifiers need their water bath to be constantly refilled when the water solution finished. These humidifiers allow condensation of patient's expired air to be evaporated during inspiration ${ }^{(27)}$.

13 :Axillary temperature is an evidence of child comfort and preference. Oral temperatures are difficult to get in children less than in five years age, rectal temperatures are not recommended for premature infants and potential for bleeding, altered immune systems and rectal abnormalities ${ }^{(28)}$.

14: Drawing all blood sampling from central line Majority of nurses use a stopcock on the central line as a part of daily lab sample routine because it minimizes time, pain and lower cost. It was observed that painful procedures 
can alter brain structure, behavioral and hormonal response to pain children who were in high risk disease (29).

15: The return of flatus first postoperative bowel movement were more helpful than bowel sounds in determining the return of gastrointestinal mobility after abdominal surgery .This evidencebased project resulted in saving nursing time ${ }^{(30)}$.

Teaching sessions for nurses was conducted as the follows:

The first session: Definition of Evidence Based Performance, Evidence based practice information as a guide to implement, infection control by hand washing.

The second session: The PICOT framework guides, lower body temperature, endotracheal intubation.

The third session: Ventilator humidifier changes, blood sample pain control and Kinetic versus standard beds

The fourth session: Application of evidence based performance.

The application of EBP Process is an inquisitive approach to clinical care. Evidence based practice performance beginnings with a clinical question and seeks to know the evidence that backing the care delivered. Evidence-based practice involves a process that can be described in a number of steps as outlined below ${ }^{(13)}$.

Step 0: Planting a spirit of inquiry. Evidence based practice performance begins by cultivating a spirit of inquiry. Clinical inquiry becomes a routine part of practice and ongoing curiosity is fostered.

\section{Step 1: Ask the PICOT question.}

(P) Patient population of interest,

(I) Intervention or area of interest,

(C) Comparison intervention or group,

(O) Outcome,

(T) Time.

Step 2: Search for the best evidence.

The PICOT framework guides the search for relevant evidence to answer the clinical question. Database searches using key words or phrases enable to identify articles to inform practice on the topic of interest.

Step 3: Critically appraise the evidence. This step involves a systematic evaluation of the articles retrieved in the search. Study results are analyzed for validity and reliability, as well as applicability to other clinical settings. Information is synthesized to determine if there is enough evidence to backing current practice or if there is a recommendation for practice change.

Step 4: Integrate the evidence with clinical expertise and patient preferences and values. Research evidence is deem along with patient assessments, clinical expertise 
and data; patients' preferences and values are also taken into account.

Step 5: Evaluate the outcomes of the EBP practice change.

After implementing an EBP change, outcomes are evaluated to determine the effect of the intervention.

Step 6: Disseminate the outcomes. Lessons learned should be shared with colleagues. (Melnyk et al., 2015) $^{(14)}$.

\section{4-Evaluation phase:}

Evaluation of nurse's knowledge and performance was done immediately and one month post implementing of Evidence based nursing guidelines using Tools II and III.

The data: Collection of data was carried out from the beginning of January, 2019 to the end of January, 2020.

Statistical analysis: The data collected were organized, tabulated and statistically analyzed using statistical science (SPSS) version 21 for windows. Descriptive statistics were applied (e.g. frequency, percentages, mean and standard deviation). Test of significance, Chi-square "X2", were used to test the study hypothesis. Reliability of the study tools was done using Cronbach's Alpha. A significant level value was considered when $\mathrm{p}<0.05$ and a highly significant level value was considered

\section{RESULTS}

Table (1): The subjects comprised 40 nurses working at Pediatric intensive care unit, concerning educational degree; near half $(47.5 \%)$ have technical degrees and only $(2.5 \%)$ holding PHD degree, more than half $(60 \%)$ of them aged less than 20 years and more than a third while the same percent (35\%) had less than 5 and from 5 to 10 years of experience while only $7.5 \%$ of them received previous EBN training.

Table (2): Demonstrates that nurses' knowledge score has been increased dramatically immediately post $97.5 \%$ compared to $22.5 \%$ in the pre implementation of evidence based guideline related to a guide to successful. In addition; the same table illustrated that less than a fifth and the same percent $15 \%$ of the nurses give correct and complete answers pre being compared to majority $95 \%$ of them immediately post the implementation of evidence based guideline related to The Steps and PICOT. More over; three fourths $75 \%$ of the nurses give incorrect answers in the pre, compared to none of them immediately post the implementation of evidence based guideline related to, definition while small and the same percent $2.5 \%$ of the nurses give correct incomplete answers immediately post compared to $45 \%, 50 \%$ 
and $30 \%$ pre the application of evidence based guideline related to endotracheal intubation, infection control by hand washing and Kinetic versus standard beds; respectively. Also, this table showed that the total mean \pm SD knowledge scores highly increased immediately after the implementation of evidence based nursing guidelines to $19.62 \pm .80$ compared to $5.25 \pm 3.67$ pre application of evidence based nursing guidelines. It was noticed that there was a high significant correlation between the total knowledge score pre and immediately post the application of evidence based nursing guidelines in all knowledge items where P 0.00 .

Table (3): Illustrated that none and the same percentage of the studied nurses give incorrect answers one month post being compared to three fourths of them $75 \%$ pre the implementation of evidence based nursing guidelines as related to; Definition and Kinetic versus standard beds. Moreover the same table presented that only a small and the same percentage $2.5 \%$ of the nurses were able to answer the questions correctly and completed in the pre implementation which has been increased dramatically to $92.5 \%, 95 \%$ and $95 \%$ as related to ; PICOT, ventilator humidifier change and Kinetic versus standard beds; respectively, one month post the implementation of evidence based nursing guidelines. In addition; less than half and same percentage $45 \%$ of the nurses give correct incomplete answers in the pre compared to the small percentage $10 \%$ and $5 \%$ one month post the implementation of evidence based nursing guidelines related to lower body temperature and endotracheal intubation respectively. It was noticed that there was a high significant correlation between total knowledge score pre and one month post implementation of evidence based nursing guidelines where $\mathrm{P}$ value equals 0.00 . Also, this table showed that the mean knowledge score highly increased one month post compared to pre the implementation of evidence based nursing guideline $5.25 \pm 3.67$ and $19.17 \pm 1.0$; respectively, with high a significant correlation.

Table 4:.It is was noticed that there was a high significant correlation between the total practice score pre and one month post the implementation of evidence based nursing guidelines where $\mathrm{P}$ value equals 0.00. Also, this table showed that the good practice score highly increased one month post being compared to pre the application of evidence based nursing guideline $85 \%$ and 17.5; respectively, with a high significant correlation. 
Table (5): Illustrated that evidence performance recommended procedures guidelines pre the application less than( $55 \%)$ and only $(70 \%),(72.5)$ in Hand washing and use of a protective gloves every approach child and Frequency of bacterial filter changes every three days respectively was recommended compared to post application evidence all recommended procedure performance take more than $(95 \%)$ such as axillary temperature measurements, replacement of humidifiers and Kinetic versus standard beds and also in follow up one months .Also it is was notice that there was a high significant correlation between evidence performance recommended procedure guideline pre and one month post implementation of evidence based nursing guidelines where $\mathrm{P}$ value equal 0.00 .

Table (6): Illustrated that not recommended evidence performance procedures guidelines pre the application more than ( 70\%) in breathing exercise, Children bed ,replacement of humidifiers each week, oral and rectal temperature measurements, venipuncture for drawing all blood sampling and hearing bowel sounds of patients who undergone abdominal surgery in pre implementation evidence based practices compared to immediate post and one month post all not recommended performances less than (5\%) where $\mathrm{P}$ value equal 0.00 .

Table (7): It is evident from the table that there was a highly statistical significant positive correlation between age and level of education with the total knowledge and total practice pre evidence based nursing guidelines implementation where $p<0.00$ each while there was no correlation between level of education immediately and one month post evidence based implementation where p .918 and .086; respectively, except the total knowledge was affected by age where $p<0.00$ one month post implementation of evidence based nursing guidelines

Table (8): Revealed that two thirds $67.5 \%$ of nurses had poor level scores of practice pre the application of evidence based nursing guidelines compared to none of them one month post the application. In addition; majority of them $85 \%$ had good the total practice levels post compared to less than fifth $17.5 \%$ pre the implementation of evidence based nursing guidelines and there was no significant correlation between the total practice level pre and one month post the guidelines application where $\mathrm{p}$ value equals .052 . 
Table 1: Percentage Distribution of the studied nurses' related to their socio demographic characteristics.

\begin{tabular}{|c|c|c|}
\hline \multirow{2}{*}{ Socio-demographic characteristics } & \multicolumn{2}{|c|}{$(n=40)$} \\
\hline & No & $\%$ \\
\hline \multicolumn{3}{|l|}{ Age } \\
\hline$-<20$ years & 24 & 60 \\
\hline$-20<40$ years & 14 & 35 \\
\hline$-40<$ years & 2 & 5 \\
\hline Mean \pm SD & \multicolumn{2}{|c|}{$2.3000 \pm .56387$} \\
\hline \multicolumn{3}{|l|}{ Sex } \\
\hline -Male & 5 & 12.5 \\
\hline -Female & 35 & 87.5 \\
\hline \multicolumn{3}{|l|}{ Level of education } \\
\hline - Technical Degree & 19 & 47.5 \\
\hline - Bachelor Degree & 18 & 45 \\
\hline - Master Degree & 2 & 5 \\
\hline - $\quad$ PhD Degree & 1 & 2.5 \\
\hline • 1otal & 40 & $100 \%$ \\
\hline \multicolumn{3}{|l|}{ Position } \\
\hline - Technical & 5 & 12.5 \\
\hline - Head of unit & 35 & $87.5 \%$ \\
\hline - Total & 40 & $100 \%$ \\
\hline Years of Experience & & - \\
\hline - $\quad<5$ years & 14 & $35 \%$ \\
\hline - $\quad 5<10$ years & 14 & $35 \%$ \\
\hline - $\quad 10<15$ years & 10 & $25 \%$ \\
\hline $\begin{array}{l}\text { - } \quad 15<20 \text { years } \\
\text { - }\end{array}$ & 2 & $5 \%$ \\
\hline & 40 & $100 \%$ \\
\hline \multicolumn{3}{|l|}{ Previous Training } \\
\hline - Yes & 3 & $7.5 \%$ \\
\hline - $\quad$ No & 37 & $92.5 \%$ \\
\hline - Total & 40 & 100.0 \\
\hline
\end{tabular}


Table 2: Distribution percentage of nurse's knowledge score pre and immediately post application of evidence based nursing guideline

\begin{tabular}{|c|c|c|c|c|c|c|}
\hline \multirow[t]{3}{*}{ Evidence-based knowledge } & \multicolumn{4}{|c|}{ Groups } & \multirow[t]{3}{*}{$\mathbf{X 2}$} & \multirow{3}{*}{$\begin{array}{l}P \\
\text { value }\end{array}$} \\
\hline & \multicolumn{2}{|l|}{ Pre } & \multicolumn{2}{|c|}{ Immediately Post } & & \\
\hline & No & $\%$ & No & $\%$ & & \\
\hline \multicolumn{7}{|l|}{ A guide to successful } \\
\hline $\mathrm{No}$ & 31 & 77.5 & 1 & 2.5 & \multirow[t]{2}{*}{46.875} & \multirow[t]{2}{*}{0.00} \\
\hline Yes & 9 & 22.5 & 39 & 97.5 & & \\
\hline \multicolumn{7}{|l|}{ Definition } \\
\hline Incorrect & 30 & 75 & 0 & 0 & \multirow[t]{3}{*}{67.105} & \multirow[t]{3}{*}{0.00} \\
\hline Correct incomplete & 9 & 22.5 & 3 & 75.5 & & \\
\hline Correct complete & 1 & 2,5 & 37 & 92.5 & & \\
\hline \multicolumn{7}{|l|}{ Steps } \\
\hline Incorrect & 15 & 37.5 & 0 & 0 & \multirow[t]{3}{*}{52.035} & \multirow[t]{3}{*}{0.00} \\
\hline Correct incomplete & 19 & 47.5 & 2 & 50 & & \\
\hline Correct complete & 6 & 15 & 38 & 95 & & \\
\hline \multicolumn{7}{|l|}{ PICOT } \\
\hline Incorrect & 15 & 37.5 & 0 & 0 & \multirow[t]{3}{*}{52.035} & \multirow[t]{3}{*}{0.00} \\
\hline Correct incomplete & 19 & 47.5 & 2 & 5 & & \\
\hline Correct complete & 6 & 15 & 38 & 95 & & \\
\hline \multicolumn{7}{|l|}{ Lower body temperature } \\
\hline Incorrect & 19 & 47.5 & 0 & 0 & \multirow[t]{3}{*}{72.290} & \multirow[t]{3}{*}{0.00} \\
\hline Correct incomplete & 20 & 50 & 1 & 2.5 & & \\
\hline Correct complete & 1 & 2,5 & 39 & 97.5 & & \\
\hline \multicolumn{7}{|l|}{ Endotracheal intubation } \\
\hline Incorrect & 22 & 55 & 0 & 0 & \multirow[t]{3}{*}{72.800} & \multirow{3}{*}{0.00} \\
\hline Correct incomplete & 18 & 45 & 2 & 2.5 & & \\
\hline Correct complete & 0 & 0 & 38 & 95. & & \\
\hline Infection control by hand v & shing & & & & & \\
\hline Incorrect & 18 & 45 & 0 & 0 & 68.581 & 0.00 \\
\hline Correct incomplete & 20 & 50 & 1 & 2.5 & & \\
\hline Correct complete & 2 & 5 & 39 & 97.5 & & \\
\hline Ventilator humidifiers chan & time & & & & & \\
\hline Incorrect & 20 & 50: & 0 & 0 & 65.200 & 0.00 \\
\hline Correct incomplete & 18 & 45 & 2 & 5 & & \\
\hline Correct complete & 2 & 5 & 38 & 95 & & \\
\hline Blood sample pain control & & & & & & \\
\hline Incorrect & 26 & 65 & 0 & 0 & 76.098 & 0.00 \\
\hline Correct incomplete & 13 & 32.5 & 0 & 0 & & \\
\hline Correct complete & 1 & 2.5 & 40 & 100 & & \\
\hline Kinetic versus standard bec & & & & & & \\
\hline Incorrect & 25 & 62.5 & 0 & 0 & 65.165 & 0.00 \\
\hline Correct incomplete & 12 & 30 & 1 & 2.5 & & \\
\hline Correct complete & 3 & $7.5 \%$ & 39 & 97.5 & & \\
\hline $\mathrm{M} \pm \mathrm{SD}$ & $\begin{array}{l}\mathrm{M} \pm \\
\text { Pre }\end{array}$ & & $\begin{array}{l}\mathrm{M}= \\
\mathrm{Pos}\end{array}$ & & $\begin{array}{l}\text { Paired } \\
\mathrm{t}\end{array}$ & Sig \\
\hline & 5.25 & & 19. & & 39 & 0.00 \\
\hline
\end{tabular}


Table 3: Distribution percentage of nurses knowledge score pre and one month post the application of evidence based nursing guidelines

\begin{tabular}{|c|c|c|c|c|c|c|}
\hline \multirow{3}{*}{$\begin{array}{l}\text { Evidence-based } \\
\text { knowledge }\end{array}$} & \multicolumn{4}{|c|}{ Groups } & \multirow[t]{3}{*}{$X$} & \multirow[t]{3}{*}{$P$ value } \\
\hline & \multicolumn{2}{|c|}{ Pre } & \multicolumn{2}{|r|}{1 Month post } & & \\
\hline & $\mathrm{No}$ & $\%$ & $\mathrm{No}$ & $\%$ & & \\
\hline \multicolumn{7}{|l|}{ Aguide to successful } \\
\hline No & 31 & $77.5 \%$ & 5 & $12.5 \%$ & \multirow[t]{2}{*}{34.141} & \multirow[t]{2}{*}{0.00} \\
\hline Yes & 9 & 22.5 & 35 & $87.5 \%$ & & \\
\hline \multicolumn{7}{|l|}{ Definition } \\
\hline In correct & 30 & $75 \%$ & 0 & $0 \%$ & \multirow[t]{3}{*}{61.1714} & \multirow{3}{*}{.000} \\
\hline Correct incomplete & 9 & $22.5 \%$ & 6 & $15 \%$ & & \\
\hline Correct complete & 1 & $2.5 \%$ & 34 & $85 \%$ & & \\
\hline \multicolumn{7}{|l|}{ Steps } \\
\hline In correct & 15 & $37.5 \%$ & 0 & $0 \%$ & \multirow[t]{3}{*}{46.211} & \multirow[t]{3}{*}{0.00} \\
\hline Correct incomplete & 19 & $47.5 \%$ & 4 & $10 \%$ & & \\
\hline Correct complete & 6 & $15 \%$ & 36 & $90 \%$ & & \\
\hline \multicolumn{7}{|l|}{ PICOT } \\
\hline In correct & 19 & $47.5 \%$ & 0 & $0 \%$ & \multirow[t]{3}{*}{65.670} & \multirow[t]{3}{*}{0.00} \\
\hline Correct incomplete & 20 & $50 \%$ & 3 & $7.5 \%$ & & \\
\hline Correct complete & 1 & 2.5 & 37 & $92.5 \%$ & & \\
\hline \multicolumn{7}{|l|}{ Lower body temperature } \\
\hline In correct & 22 & $55 \%$ & 0 & $0 \%$ & \multirow[t]{3}{*}{66.909} & \multirow[t]{3}{*}{0.00} \\
\hline Correct incomplete & 18 & $45 \%$ & 4 & $10 \%$ & & \\
\hline Correct complete & 0 & $0 \%$ & 36 & $90 \%$ & & \\
\hline \multicolumn{7}{|c|}{ Endotracheal intubation } \\
\hline In correct & 18 & $45 \%$ & 0 & $0 \%$ & \multirow[t]{3}{*}{65.127} & \multirow[t]{3}{*}{0.00} \\
\hline Correct incomplete & 20 & $50 \%$ & 2 & $5 \%$ & & \\
\hline Correct complete & 2 & $5 \%$ & 38 & $95 \%$ & & \\
\hline Infection control by han & d wa & & & & & \\
\hline In correct & 20 & $50: \%$ & 0 & $0 \%$ & 65.200 & 0.00 \\
\hline Correct incomplete & 18 & $45 \%$ & 2 & $5 \%$ & & \\
\hline Correct complete & 2 & $5 \%$ & 38 & $95 \%$ & & \\
\hline Ventilator humidifiers c & hang & & & & & \\
\hline In correct & 26 & $65 \%$ & 0 & $0 \%$ & 69.169 & 0.00 \\
\hline Correct incomplete & 13 & $32.5 \%$ & 2 & $5 \%$ & & \\
\hline Correct complete & 1 & $2.5 \%$ & 38 & $95 \%$ & & \\
\hline Blood sample pain cont & & & & & & \\
\hline In correct & 25 & $62.5 \%$ & 0 & $0 \%$ & 59.300 & 0.00 \\
\hline Correct incomplete & 12 & $30 \%$ & 3 & $7.5 \%$ & & \\
\hline Correct complete & 3 & $7.5 \%$ & 37 & $92 . \%$ & & \\
\hline Kinetic versus standarc & beds & & & & & \\
\hline In correct & 30 & $75 \%$ & 0 & $0 \%$ & 69.557 & 0.00 \\
\hline Correct incomplete & 9 & $22.5 \%$ & 2 & $5 \%$ & & \\
\hline Correct complete & 1 & $2.5 \%$ & 38 & $95 \%$ & & \\
\hline $\begin{array}{l}\text { Total knowledge } \\
(\text { mean } \pm \text { SD }\end{array}$ & $\begin{array}{l}\%( \\
\text { Pre }\end{array}$ & In \pm SD) & $\begin{array}{l}\%(1 \\
\text { Pos }\end{array}$ & SD) & Paired T & Sig \\
\hline & $(5.2$ & 67) & (19. & & 39 & 0.00 \\
\hline
\end{tabular}


Table 4: Total score of practice pre evidence, immediately post and one month post.

\begin{tabular}{|c|c|c|c|c|c|c|c|c|}
\hline \multirow[t]{2}{*}{$\begin{array}{l}\text { Total practice } \\
\text { level }\end{array}$} & \multicolumn{2}{|c|}{ Pre evidence } & \multicolumn{2}{|c|}{$\begin{array}{l}\text { Immediately } \\
\text { post }\end{array}$} & \multicolumn{2}{|c|}{$\begin{array}{ll}\text { One month's } \\
\text { post }\end{array}$} & $P$ & Sig \\
\hline & $\mathrm{N}$ & $\%$ & $\mathrm{~N}$ & $\%$ & $\mathrm{~N}$ & $\%$ & \multirow[t]{4}{*}{.201} & \multirow[t]{4}{*}{0.00} \\
\hline \multirow[t]{2}{*}{ Poor } & 27 & $67.5 \%$ & 0 & $0 \%$ & 0 & $0 \%$ & & \\
\hline & 6 & $15 \%$ & 0 & $0 \%$ & 6 & $15 \%$ & & \\
\hline Fair & 7 & $17.5 \%$ & 40 & $100 \%$ & 34 & $85 \%$ & & \\
\hline
\end{tabular}

Table 5: Distribution percentage of recommended procedures pre, immediately and one month post implementation of evidence based nursing guidelines

\begin{tabular}{|c|c|c|c|c|c|c|c|c|}
\hline \multirow{3}{*}{$\begin{array}{l}\text { Recommended } \\
\text { performance }\end{array}$} & \multicolumn{6}{|c|}{ Groups } & \multirow[t]{2}{*}{$X$} & \multirow{2}{*}{$\begin{array}{l}\mathrm{P} \\
\text { value }\end{array}$} \\
\hline & \multicolumn{2}{|l|}{ Pre } & \multicolumn{2}{|c|}{ Immediately Post } & \multicolumn{2}{|c|}{1 Month post } & & \\
\hline & No & $\%$ & No & $\%$ & No & $\%$ & 19.57 & 0.00 \\
\hline $\begin{array}{l}\text { Hand washing and use a } \\
\text { protective gloves every } \\
\text { approach child }\end{array}$ & 28 & 70 & 39 & 97.5 & 39 & 97.5 & & \\
\hline $\begin{array}{l}\text { Use of closed circuit } \\
\text { aspiration system }\end{array}$ & 20 & 50 & 40 & 100 & 39 & 97.5 & 45.65 & 0.00 \\
\hline $\begin{array}{l}\text { Oral route for } \\
\text { endotracheal intubation }\end{array}$ & 19 & 47.5 & 39 & 97.5 & 39 & 97.5 & 45.65 & 0.00 \\
\hline Spirometer therapy & 10 & 25 & 40 & 100 & 40 & 100 & 43.03 & 0.00 \\
\hline $\begin{array}{l}\text { Frequency of ventilator } \\
\text { circuit changes each week } \\
\text { for child }\end{array}$ & 22 & 55 & 40 & 100 & 40 & 100 & 45.65 & 0.00 \\
\hline $\begin{array}{l}\text { Warm blood by warmer } \\
\text { machine }\end{array}$ & 15 & 38.5 & 39 & 97.5 & 39 & 97.5 & 80.00 & 0.00 \\
\hline $\begin{array}{l}\text { Frequency of bacterial } \\
\text { filter changes every three } \\
\text { days }\end{array}$ & 29 & 72.5 & 40 & 100 & 39 & 97.5 & 45.65 & 0.00 \\
\hline $\begin{array}{l}\text { suction systems with } \\
\text { sterile water }\end{array}$ & 15 & 37.5 & 40 & 100 & 40 & 100 & 43.35 & 0.00 \\
\hline Warm compressor & 20 & 50 & 40 & 100 & 39 & 97.5 & & \\
\hline $\begin{array}{l}\text { Bladder training vacation } \\
\text { with urinary catheter }\end{array}$ & 14 & 35 & 38 & 95 & 38 & 95 & 53.52 & 0.00 \\
\hline $\begin{array}{l}\text { Kinetic versus standard } \\
\text { beds }\end{array}$ & 7 & 17.5 & 39 & 97.5 & 38 & 95 & 45.65 & 0.00 \\
\hline $\begin{array}{l}\text { Replacement } \\
\text { humidifiers }\end{array}$ & 12 & 30 & 40 & 100 & 39 & 97.5 & 20.56 & 0.00 \\
\hline $\begin{array}{l}\text { Axillary temperature } \\
\text { measurements }\end{array}$ & 11 & 27.5 & 39 & 97.5 & 38 & 95 & & \\
\hline $\begin{array}{l}\text { Drawing all blood } \\
\text { sampling from central line }\end{array}$ & 10 & 25 & 40 & 100 & 39 & 97.5 & 63.16 & 0.00 \\
\hline The return of flatus & 7 & 17.5 & 40 & 100 & 38 & 95 & 45.65 & 0.00 \\
\hline
\end{tabular}

Vol. 20 No. 1 February, 2021 
Table 6: Distribution percentage of not recommended procedures pre, immediately and one month post implementation of evidence based nursing guidelines

\begin{tabular}{|c|c|c|c|c|c|c|c|c|}
\hline \multirow{3}{*}{$\begin{array}{l}\text { not recommended } \\
\text { performance }\end{array}$} & \multicolumn{6}{|c|}{ Groups } & \multirow[t]{3}{*}{$\mathrm{X}$} & \multirow{3}{*}{$\begin{array}{l}\mathrm{P} \\
\text { value }\end{array}$} \\
\hline & \multicolumn{2}{|l|}{ Pre } & \multicolumn{2}{|c|}{ Immediately Post } & \multicolumn{2}{|c|}{1 Month post } & & \\
\hline & No & $\%$ & No & $\%$ & No & $\%$ & & \\
\hline $\begin{array}{lr}\text { Hand } & \text { washing with } \\
\text { alcohol } & \text { between } \\
\text { procedure } & \end{array}$ & 12 & 30 & 1 & 2.5 & 1 & 2.5 & 19.57 & .00 \\
\hline $\begin{array}{l}\text { Use of open suction } \\
\text { circuit aspiration system }\end{array}$ & 20 & 50 & 0 & 0 & 1 & 2.5 & 45.65 & 0.00 \\
\hline $\begin{array}{l}\text { Nasal route for } \\
\text { endotracheal intubation }\end{array}$ & 21 & 52.5 & 1 & 2.5 & 1 & 2.5 & 43.03 & 0.00 \\
\hline Breathing exercise & 30 & 75 & 0 & 0 & 0 & 0 & 80.00 & 0.00 \\
\hline $\begin{array}{l}\text { Frequency of ventilator } \\
\text { circuit changes every new } \\
\text { child }\end{array}$ & 18 & 45 & 0 & 0 & 0 & 0 & 43.35 & 0.00 \\
\hline $\begin{array}{lll}\text { Warm } & \text { blood } & \text { with } \\
\text { traditional method } & \end{array}$ & 25 & 62.5 & 1 & 2.5 & 1 & 2.5 & 53.52 & 0.00 \\
\hline $\begin{array}{l}\text { Frequency of bacterial } \\
\text { filter changes every child }\end{array}$ & 11 & 27.5 & 0 & 0 & 1 & 2.5 & 20.56 & 0.00 \\
\hline $\begin{array}{l}\text { Suction systems with } \\
\text { saline }\end{array}$ & 25 & 62.5 & 0 & 0 & 0 & 0 & 63.16 & 0.00 \\
\hline Cold compressor & 20 & 50 & 0 & 0 & 1 & 2.5 & 43.98 & 0.00 \\
\hline $\begin{array}{l}\text { Urinary catheter without } \\
\text { vacation }\end{array}$ & 26 & 65 & 2 & 5 & 2 & 5 & 51.20 & 0.00 \\
\hline Children bed & 33 & 82.5 & 1 & 2.5 & 2 & 5 & 78.81 & 0.00 \\
\hline $\begin{array}{ll}\text { Replacement } & \text { of } \\
\text { humidifiers each week }\end{array}$ & 28 & 70 & 0 & 0 & 1 & 2.5 & 68.84 & 0.00 \\
\hline $\begin{array}{l}\text { Oral and Rectal } \\
\text { temperature } \\
\text { measurements }\end{array}$ & 29 & 72.5 & 1 & 2.5 & 2 & 5 & 64.52 & 0.00 \\
\hline $\begin{array}{l}\text { Venipuncture for drawing } \\
\text { all blood sampling }\end{array}$ & 30 & 75 & 0 & 0 & 1 & 2.5 & 75.77 & 0.00 \\
\hline $\begin{array}{l}\text { Hearing bowel sounds of } \\
\text { patients who undergone } \\
\text { abdominal surgery }\end{array}$ & 33 & 82.5 & 0 & $0 \%$ & 2 & 5 & 82.85 & 0.00 \\
\hline
\end{tabular}


Table (7) Correlation between age, level of education with total knowledge, total reported practice and throughout evidence based guideline performance

\begin{tabular}{|l|l|l|l|l|}
\hline \multirow{2}{*}{\multicolumn{1}{|c|}{ Variable }} & \multicolumn{2}{c|}{ Age } & \multicolumn{2}{c|}{ Level of education } \\
\cline { 2 - 5 } & \multicolumn{1}{c|}{$\mathbf{r}$} & p-value & \multicolumn{1}{c|}{ R } & p-value \\
\hline Total knowledge pre & & & & \\
Total practice pre & $.818^{* *}$ & 0.00 & $.880^{* *}$ & 0.00 \\
\hline Total knowledge immediately post & $.841^{* *}$ & 0.00 & $.841^{* *}$ & 0.00 \\
Total practice immediately post & $.366^{*}$ & .020 & .017 & .918 \\
\hline Total knowledge 1 month post & .207 & .200 & .094 & .563 \\
Total practice 1 month post & $.491^{* *}$ & .001 & .275 & .086 \\
& .207 & .200 & .094 & .563 \\
\hline
\end{tabular}

**. Correlation is significant at 0.01 level (2-tailed).

Table (8): Distribution of the studied nurses according to their total practice level pre and after one month post evidence based guideline $(n=40)$.

\begin{tabular}{|c|c|c|c|c|c|c|}
\hline \multirow{2}{*}{ Total practice level } & \multicolumn{2}{|c|}{ Pre (40) } & \multicolumn{2}{|c|}{ After one month } & \multirow{2}{*}{$\mathrm{X} 2$} & \multirow{2}{*}{ P-value } \\
\hline & No & $\%$ & No & $\%$ & & \\
\hline Poor & 27 & 67.5 & 0 & 0 & \multirow{3}{*}{.725} & \multirow{3}{*}{.052} \\
\hline Moderate & 6 & 15 & 6 & 15 & & \\
\hline Good & 7 & 17.5 & 34 & 85 & & \\
\hline
\end{tabular}




\section{Discussion}

Evidence based guideline is an opportunity for intensive care nurses to become involved in making significant changes in nursing care. It is essential that nurses become empowered to use the knowledge available to implement evidence based nursing guidelines. Specific knowledge and skills are required to search and appraise the available evidence to determine when evidence supports the need for a practice change. Providing nurses with the time to develop these skills and ensuring support through mentors is crucial to implementation ${ }^{(31)}$. The current study revealed a great lack of nurses knowledge regarding evidence based guidelines in pediatric intensive care unit before the application of evidence based guidelines ; all nurses had a poor knowledge score level. It agrees with those by Melnyk etal .,(2012) ${ }^{(32)}$ who found over three quarters of respondents (76.2\% $(\mathrm{n}=773)$ responded that they needed more education and skills in EBP. This reflects the lack of scientific education and skills in EBP. Pravikoff etal., (2005) ${ }^{(33)}$ who found that resources such as computer and internet access should be available in intensive care units for online research and journals access, a lack of time has frequently been identified as an important barrier to applying research into practice .Also Goudreau etal.,(2015) (34) found that appropriate resources must be made available for the implementation of evidence based nursing guidelines.

The present study reflects a significant improvement of nurses knowledge after the application evidence based guidelines so they need to be encouraged to search for answers for questions regarding nursing care not only with senior colleagues but also on electronic resources and recent journal articles. Therefore, Cason there is a need that they become familiar with such modern databases and resources. Recommends that all hospitals should have educational training programs for their staff to improve adherence to evidence based guidelines. They also recommend that hospitals encourage staff involvement in educational advancement and performance improvement projects.

The result of the present study revealed that there was a significant positive correlation among nurse's knowledge and age and level of education pre the application of evidence based guidelines agree with Linton et al (2013) ${ }^{(31)}$. Evidence-based practice: collaboration between education and nursing management agree with Cason et al., 
(2007) ${ }^{(35)}$ who recommended that age may also affect the degree as to which nurses apply prevention measures in evidence based where EBP can be enculturated. Competencies can be used as a tool to support high quality care and can be built into a number of processes, such as performance appraisals, clinical ladders or other structures to aid in EBP implementation.

In the present study found that all nurses had a poor performance score pre the application evidence based practice supported by Cason et al .,(2007) ${ }^{(35)}$ who also found that nurses persist in performing practices that are not supported by evidence and also fail to implement those with ample research evidence such as using saline for endotracheal suctioning and using an air bolus to fix a placement of a nasogastric tube (NGT) are perpetuated even though there is a large body of research showing these practices are "not helpful and may even be harmful" Melnyk et al .,(2014) ${ }^{(36)}$ and Makic et al., (2011) ${ }^{(37)}$ who are in agreement with the present study and mentioned that the mean performance was low in pre-evidence guidance and increased immediately postevidence guidance. Also Cason et al .(2007) ${ }^{(35)}$ show that databases, accessing , critiquing Clinical Practice Guidelines , literature, engaging and mentoring staff throughout the steps of EBP will empower clinical staff while promoting independence.

Also Nada et al .,(2014) ${ }^{(38)}$ stat that the synthesis of large bodies of knowledge into clinical practice guidelines is one method of improving accessibility and utility of medical literature to health care professionals for the management of critically ill patients, guidelines can improve outcomes and costs of critical care to patients and institutions.

'IOM (2003) ${ }^{(10)}$ stat that evidence based guideline was chosen as one of five core competencies along with providing patient centered care, applying quality improvement principles, working in inter professional teams, and use of health information technologies .Further validating the critical role of EBP in improving quality of care.

In the present study, majority of the nurses was negative attitude towards EBP but after the application most of them was positive attitude towards EBP. Shaheen et al., (2011) ${ }^{(11)}$ stat that many factors; however, can facilitate use of EBP implementation including adequate time, education, access to information, organizational support, mentors, resources, increased awareness of and a positive 
attitude towards EBP ,this agree with Davidson et al., (2014) ${ }^{(39)}$, Cason et al., (2007) ${ }^{(35)}$, Melnyk et al., (2012) ${ }^{(32)}$. Creating a supportive organizational culture is a key to improve and sustain EBP .The following studies highlight some key facilitating factors of EBP implementation, including positive attitude, mentors, resources and education also agree with Reteas (2000) ${ }^{(40)}$ also Upton et al .,(2014) ${ }^{(41)}$,Melnyk et al., (2004) ${ }^{(42)}$ Those that reported a greater use of EBP held force beliefs about the importance of EBP and had more knowledge of EBP than those who reported less use of EBP in current practice. The presence of a research mentor and use of Cochrane Database also correlated positively with an increased application of evidence to practice.

\section{Conclusion}

The present study has shown that EBP was implement significantly associated with nurses' level of education and suggests that nurses with degrees are better placed to review and apply EBP than nurses with a lower level of education. The most common hindrance to EBP implementation was reported to be resources as high patients and few nurses, lack of resources and time to apply, lack of EBP guidelines and formal evaluation criteria can also limit their ability to advocate for EBP application.

\section{Recommendations}

Need to develop more nurse graduates and expose nurses to more research courses, as the findings show that the level of education plays a great role in EBP implementation. This will improve both nurses' academic qualification and attitudes to EBP implementation. Resource availability plays a key role in EBP implementation . There is ;therefore, a need for the hospital management to design and develop a staff working model that takes into consideration factors such as patient-to-nurse ratio, balance between routine duties, time for research and training and resources for the EBP implementation.

A follow-up study on the postgraduate nurse's role in bridging the gap in routine practices and EBP in the clinical environment enable nurses to understand of the management role in incorporating research findings into clinical and enhancing EBP application in clinical areas.

\section{Reference}

1. Carlson C, Plonczynski, D. Has the barriers scale changed nursing practice: An integrative review.Journal 
of Advanced Nursing,2008; 63(4):322-33

2. American Nurses Credentialing

3. Center. The Magnet Model Components and Sources of Evidence. Silver Spring, MD: American Nurses Credentialing Center; 2013.

4. Schaffer M, Sandau K, Diecrik L. Evidence based practice models for organizational changes: overview and practical applications. Journal Advanced Nurses. 2013; 69(5):1197-209.

5. Godshall M. Fast Facts for EvidenceBased Practice. New York, NY: Springer Publishing Co., 2010; 40(10): 404-7.

6. Newhouse R. Instruments to assess organizational readiness for evidence based practice. Journal of Nursing Administration.2010; 40(10): 404-7.

7. Talaso D. Barako C, Sabina $\mathrm{W}$,Lilian O. Factors influencing application of evidence-based practice among nurses. Available at 23 Sep https://doi.org/10. 12968/ajmw.2012;6(2):71

8. Fulton J, Lyon B, Goudreau K. (Ed). Foundations of Clinical Nurse Specialist Practice. New York: Springer Publishing Co.,2014; 2 - 32.

9. Gerrish K, Clayton J. Promoting evidence-based practice: an organizational approach. Journal
Nurses Management. 2004;12(2):11423. doi: 10.1111/j.13652834.2004.00454.

10. Kitson A, Rycroft J, Harvey G, McCormack B, Seers K, Titchen A. Evaluating the successful implementation of evidence into practice using the PARiHS framework: theoretical and practical challenges. Implement Sci. 2008;3:1. Available at doi: 10.1186/1748-5908-3-1.

11. Institute of Medicine (IOM). Health Professions Education: 2003. A Bridge to Quality .Update Institute of Medicine .2009. Roundtable on Evidence-Based Medicine.

12. Shaheen M, Schubert F. Adopting evidence-based practice in clinical decision making: nurses' perceptions, knowledge, and barriers. Journal Med Libr Assoc. 2011 ; 99(3): 229-36.

13. Davidson J, Brown C. Evaluation of nurse engagement in evidence-based practice. AACN Advanced Critical Care.2014; 25(1): 43-55.

14. Melnyk B, Fineout E, Williamson K. The seven steps of evidence-based practice. American Journal of Nursing, 2010;10(1): 51-3

15. Melnyk B, Gallagher L. Implementing the new essential evidence based practice competencies in real-world 
clinical and academic settings: moving from evidence to action in improving healthcare quality and patient outcomes. Worldview on EvidenceBased Nursing, (2015); 12(2): 67-9.

16. Cason C, Tyner T. Saunders S. Nurses' implementation of guidelines for ventilator-associated pneumonia from the centres for disease control and prevention. American Journal of Critical Care, 2007; (16) 1:28-36.

17. Muscedere J, Dodek, P, Keenan S. Comprehensive evidence-based clinical practice guidelines for ventilator-associated pneumonia: Prevention. Journal of Critical Care, 2008; 23(1):126 -137.

18. Thomas A, Galvin I. Patient safety incidents associated with equipment in critical care: a review of reports to the UK National Patient Safety Agency. Anaesthesia .2008; 63(11):1193-97.

19. Antony R, Wilkes .Heat and moisture exchangers and breathing system filters: their use in anaesthesia and intensive care. Part 2 - practical use, including problems, and their use with pediatric patient ,First published: 30 $2010: 18$.

20. David R, Magdalena S .Warming blood prior to transfusion using latent heat, published in Emergency
Medicine Australasia. 21 July 2020 by

Flinders University .p 1:2

21. Turnbull D, Fisher p, Mills G, Hughes N. Performance of breathing filters under wet conditions: a laboratory evaluation. British Journal of Anaesthesia 2005; 94: 675- 82.

22. Glanemann M, Busch T, Neuhaus P, Kaisers U. Fast-tracking in liver transplantation. Immediate postoperative tracheal extubation: Feasibility and clinical impact. Swiss Med Wkly .2007:137(2): 187-191.

23. Hall J, Guyton A, Guyton and Hall Textbook of Medical Physiology. 13th ed. Philadelphia, PA: Elsevier, Inc.; 2016.

24. Sumy D .The Effectiveness of Warm Vinegar Compress in Lowering Children Body Temperature with Acute Febrile Illness ,International Journal of Science and Research (IJSR) ISSN (Online): 2319-7064 Index Copernicus Value 2015; 6(1): 1825 .

25. Yates A . Using patency solutions to manage urinary catheter blockage. Nursing Times. Available at .2018; 114: 5, 18-21.

26. Bhandari T, Shahi S .Massive Encrustation As A Consequence of Long-termIndwellingUrethra Catheter: 
A Rare Case Report 34 Annuals of Medicine and Surgery. Ann Med Surg (Lond).2018;29(34):14-16.

27. Anthony D ,Hilary G ,Kevin B , Danny J . Kinetic bed therapy to prevent nosocomial pneumonia in mechanically ventilated patients: a systematic review and metaanalysisCrit Care. 2006; 10(3): 70.

28. Siempos I, Vardakas K, Kopterides P, Falagas M. Impact of passive humidification on clinical outcomes of mechanically ventilated patients: a meta-analysis of randomized controlled trials. Crit Care Med. 2007;35(12):2843-51.

29. Ryan N, Sims M, Patton R , Williamson J. Selection of the most accurate thermometer devices for clinical practice: Part 1: Meta-analys is of the accuracy of non-core thermometer devices compared to core body temperature. Pediatric Nursing, 2018; 44(3): 116-133.

30. Mendez, S. Evidence-Based Practice for Obtaining Blood Specimens From a central venous access Device. Oncology Nursing Forum. 2012; 39(3): 247-251.

31. Madsen D, Sebolt T, Cullen L, Folkedah B, Mueller T, Richardson C. Listening to bowel sounds: An evidence-based practice project. American Journal of Nursing, 2005; 105 (12): 40-9.

32. Linton M, Prasun M. Evidence-based practice: collaboration between education and nursing management. Journal of Nursing Management, (2013); 21(1):5-16.

33. Melnyk B, Fineout E, Gallagher L, Kaplan L. The state of evidence-based practice in US nurses. The Journal of Nursing Administration, 2012; 42(9): 410-17.

34. Pravikoff D, Tanner A, Pierce S. Readiness of U.S. nurses for evidencebased practice. American Journal of Nursing, 2005; 105(9): 40-51.

35. Goudreau K. Health policy...so what? Clincal Nurse Specialist, 2015; 29(3): 127-8.

36. Cason C, Tyner T, Saunders S. Nurses' implementation of guidelines for ventilator-associated pneumonia from the centres for disease control and prevention. American Journal of Critical Care. 2007; 16( 1):28-36.

37. Melnyk B, Gallagher L, Long L, Fineou E. The establishment of evidence-based practice competencies for practicing registered nurses and advanced practice nurses in real-world clinical settings: proficiencies to 
improve healthcare quality, reliability, patient outcomes, and costs. Worldviews on Evidence-Based Nursing, 2014;11(1): 5-15.

38. Makic M , VonRueden K, Rauen C, Chadwick J. Evidence-based practice habits: putting more sacred cows out to pasture. Critical Care Nurse, 2011; 31(2): 38-62.

41. Upton D, Upton P, Scurlock L. The reach transferability and impact of the Evidence-Based Practice Questionnaire: A methodological and narrative literature review. Worldviews on Evidence-Based Nursing. 2014; 11(1):46-54.
39. Nada M, Rhama A ,Khald E, Hend E. Evidence based nursing practice for pediatric age grouped undergoing liver transplantation .Tanta Scientific Nursing Journal: 2014;6(1): 114-30.

40. Davidson J, Brown C .Evaluation of nurse engagement in evidence-based practice. AACN Advanced Critical Care .2014; 25(1):43-55. 